\title{
It could only happen in the movies
}

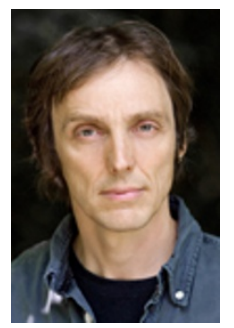

Real science can't compete at the movies with bad science. But perhaps that's how it is meant to be.

Philip Ball

"I'm arresting you for breaking the laws of physics," says the policeman to the levitating man, in a cartoon that speaks volumes about the curiously legalistic terminology that science sometimes adopts.

In this spirit, two physicists at the University of Central Florida in Orlando seem intent on making a citizen's arrest of all of Hollywood. In a preprint, they examine some egregious physical errors in recent blockbusters 1 .

Hollywood's contempt for science is notorious. From loud explosions in deep space to genetically engineered spiders that transmute man into semi-arachnid, the movies are littered with nonsense.

Does it matter? A lot, say Costas Efthimiou and Ralph Llewellyn. They argue that science bloopers in movies "contribute to science illiteracy". Hollywood, they say, "is reinforcing, or even creating, incorrect scientific attitudes that can have negative results for society".

If that is true, I suspect it's not in the way they think it is. For decades, Hollywood has endorsed the archetype of the mad scientist 2 image that vastly predates cinema ${ }^{3}$. But recent movie scientists are more nuanced: they are sometimes saviours (Armageddon), sometimes tortured geniuses (A Beautiful Mind), and — strangest of all — sometimes sexy (Jeff Goldblum in Jurassic Park).

\section{Breaking laws}

But Efthimiou and Llewellyn are less concerned with science's image than with its veracity. They explain (with equations) why the bus in Speed couldn't jump over a gap in a horizontal bridge segment of highway, why the Green Goblin in Spiderman couldn't hold up the cable of the New York tramway, and why Magneto in X-Men: The Last Stand would have to glow like a lightbulb and lose 600 kilograms of body weight to shift the Golden Gate Bridge 5 kilometres.

At face value, their analysis tilts at windmills. Let's suppose, say, that the makers of X-Men appreciated that Magneto would need to emit about 18 million watts per square metre to move the bridge. Would viewers, seeing him become incandescent, think: "Ah — blackbody radiation". Or might they think: "Ah — superpowers make you glow"?

But Hollywood's scientific absurdities do raise some interesting questions. Can we spot physics abuse? And when we see superheroic feats, do we sense that laws are being broken?

Our understanding of sporting prowess comes at the same questions from the opposite direction. No one supposes that baseball fielders or football players use newtonian mechanics to predict trajectories; rather, they seem to have a superior intuitive sense of its dynamical consequences.

The answers might imply interesting things about how much evolution has honed our senses to appreciate the laws of physics. British biologist Lewis Wolpert has argued persuasively that, on the contrary, much of science depends on subverting intuitive reasoning about the world 4 .

\section{Modern myths}

Should we endorse the violations of physics routinely perpetrated by Hollywood? Efthimiou and

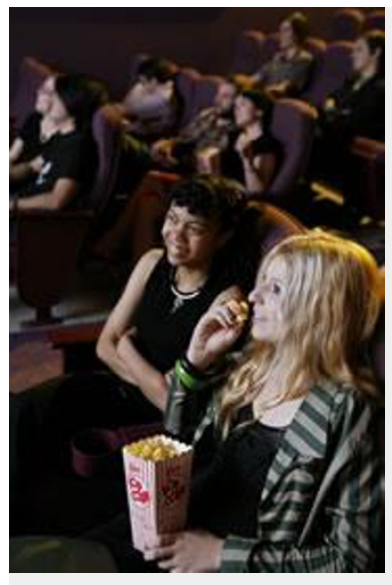

"Harry should have blacked out from the g's on that broomstick turn." Punchstock

Llewellyn clearly think not. I would argue that you might as well complain about 'errors' in the Greek myths or fairy tales, or Warner Brothers cartoons.

Blockbuster movies are the modern equivalents of classical myths, their scenarios so unashamedly fantastic that we have no illusions about what we're getting. The challenge for moviemakers is not how to respect physical laws, but rather how to break them while retaining an illusion of plausibility.

And the exploits of superheroes have been used to good effect in physics education 5 (see 'Superheroes make physics fun'). Efthimiou and Llewellyn acknowledge that movie physics can be used to cultivate students' skills at making back-of-the-envelope estimates ${ }^{6}, 7$.

Real science

Nonetheless, if you crave an antidote to Hollywood science, you can find it on YouTube, where 18 scientists working to make gas sensors from carbon nanotubes are posting video diaries of their progress. 
In the project, called Nano ${ }^{2}$ Hybrids, the Belgium-based scientists — with help from a documentary maker — are recording their results on a website where viewers can leave feedback.

The aim is to show that research really works. So I expect to see weeks of frustration as experiments fail, lots of staring at computer screens, tedious late-night observational runs, and some non-PG language when the referees' reports arrive. It's already reassuring to see so few white lab coats.

This isn't the first attempt to put science on YouTube (see here, for example). But it may be the first to try to fully document a research project this way. That could be informative, not least because it should explode some myths about what scientists do and how they behave.

But I doubt that a scientist describing her results in front of a laptop will compete with Spiderman swinging around Manhattan. And that's as it should be, because fantasy is not supposed to be constrained by the mundane laws that confound scientists in the lab.

\section{Visit our couldonlyhappeninthemo.html">newsblog to read and post comments about this story.}

\section{References}

1. Efthimiou, C. J. \& Llewellyn, R. A. http://xxx.arxiv.org/abs/0707.1167 (2007).

2. Frayling, C. Mad, Bad, and Dangerous: The Scientists and the Cinema . (Reaktion Books, 2005).

3. Haynes, R. From Faust to Strangelove: Representations of the Scientist in Western Literature. (Johns Hopkins University Press, 1994).

4. Wolpert, L. The Unnatural Nature of Science (Faber, 1992).

5. Gresh, L. H. \& Weinberg, R., The Science of Superheroes (Wiley, 2002).

6. Efthimiou, C. J. \& Llewellyn, R. A. http://xxx.arxiv.org/physics/0303005 (2003).

7. Efthimiou, C. J. \& Llewellyn, R. A. http://xxx.arxiv.org/physics/060805 (2007). 